\title{
ESCRITÓRIOS DE PROJETOS COMO RESPOSTA ESTRATÉGICA DA ORGANIZAÇÃO: UM ESTUDO DE CASO NA VALE
}

\section{Henrique Cordeiro Martins}

Doutor em Administração pela Universidade Federal de Minas Gerais - UFMG

Professor dos Programas de Mestrado e Doutorado em Administração da Universidade FUMEC

E-mail: hcmartin@ig.com.br (Brasil)

\section{Myrian Teixeira Moura}

Mestre pela FEAD Minas - Centro de Gestão Empreendedora

Consultora da PMC Consultores Ltda

E-mail: myrian.moura@terra.com.br (Brasil)

\section{José Marcos Carvalho de Mesquita}

Doutor em Administração pela Universidade Federal de Minas Gerais - UFMG

Professor dos Programas de Mestrado e Doutorado em Administração da Universidade FUMEC

E-mail: jose.mesquita@fumec.br (Brasil) 


\title{
ESCRITÓRIOS DE PROJETOS COMO RESPOSTA ESTRATÉGICA DA ORGANIZAÇÃO: UM ESTUDO DE CASO NA VALE
}

\section{RESUMO}

A gestão de projetos emergiu como uma alternativa competente para viabilizar mudanças organizacionais. O objetivo do trabalho foi examinar a configuração de Escritórios de Projetos, investigando como ela é influenciada pela estratégia e estrutura organizacionais para atender às demandas do ambiente, bem como sua adequação para favorecer o atingimento dos objetivos estratégicos da organização. Para isso, foi conduzido um estudo de caso qualitativo em três Escritórios de Projetos da Vale. Os resultados encontrados indicam que as demandas ambientais influenciam a estratégia de curto e médio prazo da organização, enquanto a estratégia de longo prazo foi a principal influência nas alterações da estrutura, inclusive com a criação dos Escritórios de Projetos investigados. A estratégia organizacional foi também a influência determinante na configuração dos Escritórios.

Palavras-chave: Escritório de Projetos; Gerenciamento de Projetos.

\section{OFFICE OF STRATEGIC PROJECTS AS ANSWER THE ORGANIZATION: A CASE STUDY IN THE VALLEY}

\begin{abstract}
Project management has emerged as a competent alternative to enable organizational changes. The objective of this study was to examine the configuration of Office Project, investigating how it is influenced by strategy and organizational structure to meet the demands of the environment as well as their suitability for promoting the achievement of strategic objectives of the organization. For this, we conducted a qualitative case study in three Vale's project offices. The results indicate that environmental demands influence the organization strategy of short and medium term, while the long-term strategy was the main influence on changes in the structure, including the creation of project office investigated. The organizational strategy was also to influence the configuration of the offices
\end{abstract}

Keywords: Project Management Office; Project Management.

Revista de Gestão e Projetos - GeP, São Paulo, v. 2, n. 2, p 26-54, jul./dez. 2011. 


\section{INTRODUÇÃo}

O gerenciamento de projetos vem crescendo, exponencialmente, na medida em que as empresas absorvem a ideia de que os projetos estão se tornando mais e mais importantes em seu negócio, e que o uso consistente de suas técnicas de gestão potencializam um aumento da qualidade, eficiência e agilidade (KERZNER, 2003; SBRAGIA, RODRIGUES e GONZÁLEZ, 2002; VERZUH, 2000).

Entretanto, é preciso organizar a gestão dos projetos de modo a viabilizar a transferência do conhecimento e a experiência obtidas em um projeto para os demais. É necessário lidar com a demanda imediata por gerenciamento eficaz e por visões integradas e informações consolidadas sobre estes projetos. E ainda avaliar o desempenho e otimizar a produtividade do conjunto de projetos que são gerenciados na organização, com volume e complexidade crescentes.

Surgem, então, áreas ou departamentos cujo propósito principal é atender às necessidades de gerenciamento do conjunto de projetos da organização onde foram criados, conhecidas cada vez mais como Project Management Office - PMO ou Escritório de Gestão de Projetos - EGP ou ainda, simplesmente, Escritório de Projetos. O Escritório de Projetos é um conceito novo, em rápida evolução, com múltiplas possibilidades de modelos, funções e nomes (BARCAUI, 2003; BRIDGES e CRAWFORD, 2000; ENGLUND, GRAHAM e DINSMORE, 2003).

Prado (2000, p.89) descreve o Escritório de Projetos como "um pequeno grupo de pessoas que tem relacionamento direto com todos os projetos da empresa, seja prestando consultoria e treinamento, seja efetuando auditoria e acompanhamento de desempenho dos projetos". Na visão de Valeriano (2005), o escritório de projetos consiste em uma estrutura formal, instalada em uma organização e dedicada a apoiar sua comunidade de gerenciamento de projetos e a seus próprios projetos.

Vários autores vêm associando o alinhamento metodológico dos projetos e o alinhamento estratégico da carteira de projetos com o negócio como atribuições características de um PMO ou EGP (DINSMORE, 2003; VARGAS, 2005; RAD e LEVIN, 2002; PMI, 2006a). A capacidade de associar os projetos às metas operacionais e estratégicas de uma organização tem implicações de longo prazo em relação ao uso de seus recursos. O gerenciamento integrado da carteira de projetos permite que a visão dos planos estratégicos seja equilibrada com a realidade da limitação, ou da melhor opção, de uso dos recursos de cada organização (KERZNER, 2002; DINSMORE, 2003).

Revista de Gestão e Projetos - GeP, São Paulo, v. 2, n. 2, p 26-54, jul./dez. 2011. 
No desafiador cenário atual de competitividade global, estimulado pelo boom econômico que se evidencia pela alta cíclica de preços das commodities minerais (matérias-primas minerais cotadas no exterior), as empresas do setor mineral passaram a depender diretamente de sua capacidade de se ajustar aos grandes movimentos do mercado, isto é, de viabilizar a expansão da sua produção e garantir o atendimento da demanda (DNPM, 2007a). No processo de aprendizagem sobre como enfrentar este curso evolutivo, incontestável e continuado, emergem novas tecnologias gerenciais. Em empresas da indústria mineral, a efetivação das mudanças por meio do gerenciamento de projetos destacou-se como alternativa capaz de garantir novos posicionamentos estratégicos, viabilizando a consecução de objetivos que envolvem complexidade técnica e alocação de recursos consideráveis, assim como melhoria contínua e redução de custos.

A criação de uma área capaz de suportar tais empreendimentos e potencializar o resultado dos múltiplos projetos foi o passo seguinte. Na medida em que surgiram movimentações no sentido de padronizar técnicas e práticas para a instituição, bem como capacitá-la para traduzir sua estratégia organizacional em projetos consistentes e bem sucedidos, o assunto e o conceito do Escritório de Projetos, adquiriram atenção e dimensão (KERZNER, 2002; DISNMORE, 2003). Um Escritório de Projetos é implementado sobre a crença de que as metas da empresa serão alcançadas por meio de uma abordagem sistêmica, e inclui projetos estratégicos, melhoria operacional e transformação organizacional, assim como a gestão tradicional de projetos, segundo pensam Englund, Graham e Dinsmore (2003). A condução intencional de um conjunto selecionado de projetos por meio de um Escritório de Projetos promove, na opinião de Rad e Levin (2002), muito mais do que a eficiência e eficácia da organização em termos da coordenação de recursos, custos e interfaces: torna consistente a operacionalização de seu plano estratégico.

Considerando este cenário, o objetivo desse artigo é examinar a configuração de Escritórios de Projetos da Vale, investigando como ela é influenciada pelas dimensões organizacionais (estratégia e estrutura) para atendimento às demandas do ambiente e se esta configuração contribui para o atingimento dos objetivos estratégicos da organização.

O Escritório de Projetos parece revelar-se como solução capaz de alinhar os projetos aos objetivos estratégicos do negócio por incorporar, ao gerenciamento de projetos, uma perspectiva empresarial. O setor mineral, no particular, a partir do Plano Plurianual - PPA 2004-2007, foi reconhecido pelo governo federal como um dos três pilares de sustentação do desenvolvimento do Brasil (DNPM, 2007a). Com objetivos estratégicos bem definidos e sempre atentos as questões econômica, social, ambiental e de desenvolvimento regional integrado e sustentável, as

Revista de Gestão e Projetos - GeP, São Paulo, v. 2, n. 2, p 26-54, jul./dez. 2011. 
organizações do setor mineral estão empenhadas na busca pelo sucesso de seu negócio, particularmente importante com relação à diminuição da vulnerabilidade externa da economia nacional.

\section{REFERENCIAL TEÓRICO}

\subsection{A GESTÃO DE PROJETOS}

Projeto é uma abordagem estruturada, para que as organizações viabilizem as adaptações ou transformações necessárias para atender aos desafios e às oportunidades demandadas por um ambiente dinâmico e competitivo. Por permitirem organizar atividades que não podem ser abordadas dentro dos limites rotineiros da operação, aponta o Project Management Institute (PMI, 2004), freqüentemente os projetos são um meio para se atingir o plano estratégico da organização.

De acordo com o Project Management Book of Knowledgement ou, simplesmente, o PMBoK (PMI, 2004, p. 5), gerenciar um projeto inclui (a) identificar uma necessidade, (b) estabelecer objetivos que sejam claros e alcançáveis, (c) balancear demandas potencialmente conflitantes de qualidade, escopo, tempo e custo, e (d) adaptar abordagem, planos e especificações em função das diversas partes interessadas e suas respectivas expectativas e preocupações.

Dinsmore (2003, p.33) propõe que projetos bem sucedidos exigem "o preenchimento da lacuna entre a visão da empresa e os projetos em andamento, o que por sua vez requer coordenação entre estratégias corporativas, o alinhamento geral dos projetos, o alinhamento de projetos específicos e a implementação de projetos". E considera uma segunda visão sobre a gestão de projetos, mais importante e mais moderna, aquela que considera o contexto organizacional, envolvendo múltiplos projetos, questões organizacionais relacionadas a estes projetos e seu alinhamento com as estratégias do negócio.

Em 2006, o PMI - Project Management Institute, órgão responsável pela metodologia de maior amplitude de aplicação em nível mundial, publicou dois novos padrões metodológicos que avançam em termos do esclarecimento sobre funções e responsabilidades do Escritório de Gestão de Projetos na gestão de carteiras de projetos: o padrão para gerenciamento de programas e o padrão de gerenciamento de portfólio (PMI, 2006a). De acordo com o PMI (2006a), um programa é um grupo de projetos relacionados entre si e gerenciados de forma coordenada, com o objetivo de se 
obter benefícios e efetivo controle que não seriam possíveis individualmente. Sua gestão consiste do gerenciamento centralizado e coordenado para atingimento dos benefícios e os objetivos estratégicos da organização.

Um portfólio é um conjunto de projetos e/ou programas reunidos para facilitar seu gerenciamento eficaz, cujo propósito é atender aos objetivos de negócios estratégicos. É identificada como operação contínua, distinta da gestão de projetos e programas (PMI, 2006a). Parece tornar-se necessária a criação de uma interface mais forte entre o planejamento de negócios e a gestão estratégica de projetos, acredita Dinsmore (2003). Por esta razão, este autor argumenta que alinhar o portfólio de projetos com os objetivos da organização demanda uma coordenação formal, assegurando que as ações de cada projeto sejam desenvolvidas para atingimento dos objetivos corporativos.

\subsection{O ESCRITÓRIO DE GESTÃO DE PROJETOS}

O Escritório de Projetos deve ser uma estrutura que favoreça ao plano estratégico da organização e torne possível maximizar o cumprimento de seus objetivos, que aproxime a concepção da estratégia, desenvolvida pela alta administração, de seu braço executor (DINSMORE, 2003).

Se a gestão de projetos permite desdobrar a estratégia para toda a organização, é por meio dos Escritórios de Projetos, como unidades ou estruturas centralizadoras desta competência, que se dá o alinhamento e a sustentação ativa com o planejamento estratégico da organização (KEZNER, 2002; KING, 1993). A adoção e o desenvolvimento da metodologia de gerenciamento de projetos demandam transformações profundas na cultura organizacional (RABECHINI, 2003; DINSMORE, 2003). O próprio entendimento do Escritório de Projetos como elemento importante na geração de resultados desejados aos negócios da organização, seja pelo melhor desempenho dos projetos, seja por sua função de suporte ao planejamento estratégico das organizações, influencia o próprio processo de sua criação e implementação. (DINSMORE, 2003)

A gênese do Escritório de Projetos está relacionada com os departamentos de projetos existentes no final da década de 1950 e no início dos anos 1960, cuja atuação se restringia aos grandes projetos e atendimento a um único cliente. Estes departamentos tinham como principais funções a manutenção dos cronogramas e a preparação de documentos para o cliente, sendo habitualmente associados ao espaço físico que ocupavam (KERZNER, 2002; KERZNER, 2003).

Revista de Gestão e Projetos - GeP, São Paulo, v. 2, n. 2, p 26-54, jul./dez. 2011. 
Englund, Graham e Dinsmore (2003) já reconhecem o surgimento dos Escritórios de Projetos apenas ao final da década de 1980, quando as organizações se deram conta do significado efetivo dos projetos para seu negócio. Kerzner (2002) argumenta, ainda, que apenas durante a recessão econômica ocorrida na década de 1990, a gestão de projetos se expandiu para indústrias não orientadas para projetos. Reconhecendo o efeito desta profissionalização sobre os resultados, as organizações buscaram identificar e concentrar as atividades críticas relativas à gestão de projetos sob uma supervisão de uma mesma estrutura. Nasce o moderno Escritório de Projetos: um "centro de excelência” em gestão de projetos.

A partir do ano 2000, o Escritório de Projetos torna-se uma estrutura comum na hierarquia das grandes organizações, em função da gestão de projetos ter crescido de forma quase exponencial nas organizações. Embora a maioria das atividades da década anterior tenha permanecido, oferecendo estrutura, disciplina e metodologia para garantir o trabalho a ser realizado, no entendimento de Kerzner (2002, p. 268), agora ele tem uma nova missão: "manter toda a propriedade intelectual relativa à gestão de projetos e de ativamente sustentar o planejamento estratégico da corporação".

Cada organização modela e dirige seu EGP segundo as prioridades que ela entende possam assegurar o atingimento de suas metas (CRAWFORD, 2002; RAD e LEVIN, 2002). Escritórios de projetos variam tanto quanto variam as culturas organizacionais: encontra-se na literatura uma grande diversidade de tipos, funções, níveis, nomes e estruturas de EGP. Tal variedade pode ser compreendida em função de aspectos como a maturidade da organização em relação à gestão de projetos, a importância dos projetos para o negócio, o porte da organização e de seus projetos, o tipo de estrutura organizacional encontrados, dentre outros aspectos (Dinsmore, 2003; Kerzner, 2003; Sbragia, Rodrigues e González, 2002).

\subsubsection{MODELOS DE ESCRITÓRIOS DE GESTÃO DE PROJETOS}

Para decidir sobre a configuração mais adequada, Bridges e Crawford (2001) afirmam que deve ser considerada a composição da carteira do escritório a ser atendida, tanto em função do nível de maturidade em gestão de projetos, quanto das metas da organização. Também deve ser avaliado o impacto do EGP em relação à cultura da organização e do segmento onde ela atua. Pode-se, então, definir o posicionamento hierárquico-funcional, o foco de atuação e as funções a serem realizadas, caracterizando-se o nível adequado do escritório de projetos para a organização, tal como pode ser observado no Quadro 1.

Revista de Gestão e Projetos - GeP, São Paulo, v. 2, n. 2, p 26-54, jul./dez. 2011. 
Considerando o conjunto de atribuições, Dinsmore (2003) caracterizou quatro tipos "clássicos" de escritórios de projetos, que podem ser encontrados em sua forma "pura" ou híbrida: (a) Se o EGP possui foco operacional e presta serviços a vários gerentes de projetos, simultaneamente, assegurando recursos técnicos, estabelecendo padrões metodológicos, facilitando comunicação e capacitando pessoas, ele é um Escritório de Suporte a Projetos (Project Office PO). (b) Quando o escritório busca aumentar a competência organizacional em gestão de projetos, sem, contudo, se responsabilizar pelos resultados dos projetos, ele é um Centro de Excelência em Gestão de Projetos (Project Management Center Of Excellence - PMCOE). Seu foco de atuação é metodológico e ele fornece patrocínio, desenvolvimento de competências e divulgação de melhores práticas; (c) A Superintendência de Gestão de Projetos (Program Management Office - PMO) combina em sua atuação tanto a prestação de serviços de suporte quanto a excelência metodológica, com sólida base política. Responde pelos resultados alcançados pelos projetos / programas sob sua responsabilidade, provendo reportes consolidados e visão global dos resultados agregados. (d) $\mathrm{O}$ quarto modelo possui foco essencialmente estratégico e parece fazer sentido em organizações globais, multidisciplinares, orientadas para empreendimentos complexos: é a Diretoria Executiva de Projetos (Chief Project Office ou Executive Project Management Office - CPO ou EPMO). Responde pela interface com a alta administração, prioriza recursos e decide sobre novos negócios, participa do planejamento estratégico e supervisiona projetos prioritários.

\begin{tabular}{|c|c|c|c|}
\hline & \multicolumn{3}{|c|}{ CARACTERÍSTICAS POR NÍVEL } \\
\hline $\begin{array}{l}\text { VARIÁVEL DE } \\
\text { CONFIGURAÇÃOO }\end{array}$ & NÍVEL 1 & NÍVEL 2 & NÍVEL 3 \\
\hline TIPO DE CARTEIRA & $\begin{array}{l}\text { Um grande projeto ou } \\
\text { programa }\end{array}$ & $\begin{array}{c}\text { Portfólio de projetos do } \\
\text { departamento ou divisão } \\
\text { Projetos especiais entre } \\
\text { áreas }\end{array}$ & $\begin{array}{l}\text { Portfólio de projetos da } \\
\text { organização }\end{array}$ \\
\hline $\begin{array}{c}\text { DEMANDAS } \\
\text { ORGANIZACIONAIS } \\
\text { PARA PROJETOS }\end{array}$ & $\begin{array}{l}\text { - Cumprir as metas do } \\
\text { projeto ou programa } \\
\text { - Gerar base de } \\
\text { conhecimento }\end{array}$ & $\begin{array}{l}\text { - Coordenar e integrar } \\
\text { recursos, reportes, controles } \\
\text { e requisições } \\
\text { - Garantir consistência do } \\
\text { processo entre os projetos } \\
\text { - Consolidar e reportar } \\
\text { informações, controles, } \\
\text { orçamentos }\end{array}$ & $\begin{array}{l}\text { - Ser um centro de } \\
\text { excelência em GP } \\
\text { - Fornecer uma visão } \\
\text { integrada dos projetos do } \\
\text { negócio } \\
\text { - Promover o alinhamento } \\
\text { dos projetos com o plano } \\
\text { estratégico da organização }\end{array}$ \\
\hline
\end{tabular}

Revista de Gestão e Projetos - GeP, São Paulo, v. 2, n. 2, p 26-54, jul./dez. 2011. 
POSICIONAMENTO

HIERÁQUICO-

FUNCIONAL
Em nível do desenvolvimento do projeto

Quadro 1- Caracterização dos escritórios de projetos por nível.

Fonte: Adaptado de Bridges e Crawford, 2001.

\subsubsection{A TRÍADE DA CONFIGURAÇÃO: O NÍVEL DE ATUAÇÃO, AS ATRIBUIÇÕES E O ALINHAMENTO DO EP COM O NEGÓCIO}

A configuração e a estratégia de implementação de um EGP devem focar, prioritariamente, o atendimento às necessidades da organização e às oportunidades imediatas de geração de valor (BRIDGES e CRAWFORD, 2000, p.8). Englund, Graham e Dinsmore (2003), assim como Crawford (2002) e Hill (2008), acreditam que, para eleger o conceito e o desenho adequados às necessidades e requerimentos da organização, vários aspectos da própria organização e de seus projetos devem ser considerados.

A adequação do nível de atuação do Escritório de Projetos pode ser avaliada em função do tipo de carteira a ser atendido (quantos e quais projetos e programas), associado às expectativas da organização em relação a projetos (motivação para implementação do EGP e requerimentos a serem atendidos) e ao seu posicionamento da estrutura hierárquico-funcional da organização (em nível técnico, intermediário ou institucional), segundo Bridges e Crawford (2002). Foi ainda inserida nesta dimensão uma variável especificando a composição da equipe (empregados, terceiros ou mista) e a estrutura funcional do Escritório estudado (Quadro 2).

As atribuições pelas quais o escritório de projetos responde, apontam para um perfil cuja propriedade pode ser avaliada considerando-se o porte quantitativo e financeiro da carteira, a autonomia na gestão de recursos e o foco de atuação e funções associadas: operacional, metodológico, tático e estratégico (BRIDGES e CRAWFORD, 2001; DINSMORE, 2003).

O alinhamento do escritório de projetos com o negócio reflete se sua configuração favorece o atingimento do plano estratégico organizacional e departamental, e em termos operacionais, pode ser avaliado pela composição da carteira sob sua responsabilidade, ou seja, pela aderência dos projetos aos objetivos estratégicos; pelo compromisso com os resultados alcançados por ela alcançados; pela participação nas decisões sobre a carteira e seus os projetos (seleção, priorização e manutenção da carteira).

Revista de Gestão e Projetos - GeP, São Paulo, v. 2, n. 2, p 26-54, jul./dez. 2011. 


\begin{tabular}{|c|c|}
\hline DIMENSÃO DA CONFIGURAÇÃO & VARIÁVEIS OPERACIONAIS \\
\hline \multirow{4}{*}{ NÍVEL DE ATUAÇÃO } & - Tipo de carteira atendida \\
\hline & - Motivação para implementação \\
\hline & - Expectativas e requerimentos a serem atendidos \\
\hline & $\begin{array}{l}\text { - Posicionamento da estrutura hierárquico-funcional } \\
\text { - Equipe e estrutura funcional }\end{array}$ \\
\hline \multirow{4}{*}{ ATRIBUIÇÕES } & - Porte quantitativo e financeiro da carteira \\
\hline & - Autonomia na gestão de recursos \\
\hline & - Foco de atuação \\
\hline & - Funções atribuídas \\
\hline \multirow{3}{*}{ ALINHAMENTO COM O NEGÓCIO } & $\begin{array}{l}\text { - Estratégia de implementação } \\
\text { - Aderência dos projetos aos objetivos estratégicos }\end{array}$ \\
\hline & $\begin{array}{l}\text { - Compromisso com os resultados alcançados pela carteira } \\
\text { atendida }\end{array}$ \\
\hline & $\begin{array}{l}\text { - Participação nas decisões sobre a carteira e seus os projetos } \\
\text { - Resultados alcançados }\end{array}$ \\
\hline
\end{tabular}

Quadro 2- Dimensões de Configuração dos Escritórios de Projetos.

Fonte: Elaborado pelos autores.

Revista de Gestão e Projetos - GeP, São Paulo, v. 2, n. 2, p 26-54, jul./dez. 2011. 


\section{METODOLOGIA}

A pesquisa realizada foi de natureza qualitativa, do tipo descritiva. No que diz respeito aos meios de investigação, a estratégia de pesquisa é um estudo de caso, no qual foram levantadas as ações dos envolvidos no processo e sua interpretação em contexto. A unidade de análise escolhida foi uma organização da indústria mineral, privada, nacional de atuação global: a Vale. A amostra foi intencional por julgamento e sua seleção buscou unidades que fossem representativas da população de Escritórios de Projetos da Vale, tendo por critérios (1) sua existência formal e atuante; (2) sua configuração como um Escritório de Projetos para cada grupo do tripé funcional da Vale (operação, administração e serviços compartilhados) e (3) sua representatividade dentro do departamento no qual foi criado. Dos nove Escritórios de Projetos Vale identificados numa pesquisa preliminar realizada, foram selecionados três para este estudo: um escritório de projetos de operações, um de administração e um de serviços compartilhados. Para cada um dos três Escritórios de Projetos definidos para o estudo foram entrevistados três membros da equipe (operações: GE1, GE2, EE3; administração: GA1, GA2, GA3; serviços: GC1, GC2, EC3), lotados na própria estrutura como empregados, parceiros internos ou parceiros contratados de terceiros, e um empregado do departamento responsável pelo planejamento estratégico da empresa (gerente de planejamento: GPE), totalizando 10 entrevistas semi-estruturadas. Os participantes da pesquisa foram selecionados em função de sua vinculação efetiva com os Escritórios de projetos, bem como de seu conhecimento sobre sua formação. Embora a empresa e as áreas tenham sido identificadas, a identidade dos entrevistados foi preservada e não aparecem nomes neste estudo.

$\mathrm{Na}$ análise dos dados foi utilizada a técnica de análise de conteúdo. O nível de atuação, as atribuições e o alinhamento com o negócio foram identificados como categorias-chave para (1) caracterizar a configuração e a atuação do EGP e (2) verificar sua contribuição para a realização do plano estratégico da empresa.

Revista de Gestão e Projetos - GeP, São Paulo, v. 2, n. 2, p 26-54, jul./dez. 2011. 


\section{APRESENTAÇÃO E ANÁLISE DOS RESULTADOS: O CASO VALE}

A Companhia Vale do Rio Doce, a Vale, é a segunda maior mineradora diversificada do mundo e a segunda maior empresa privada da América Latina, com uma capitalização, aproximada, de US\$150 bilhões no mercado (VALE, 2008). É a maior produtora mundial de minério de ferro e pelotas, insumos essenciais para a indústria siderúrgica, e uma das maiores produtoras de níquel. Produz também importantes matérias-primas para o setor industrial global tais como manganês, cobre, bauxita, alumina, alumínio, potássio, caulim, carvão, entre outras.

Ao longo de sua história, a Vale expandiu sua atuação do Brasil para o mundo, diversificando o portfólio de produtos minerais e consolidando a prestação de serviços logísticos. Está presente em 13 estados brasileiros e em 32 países além do Brasil, em cinco continentes: Américas, Europa, África, Ásia e Oceania, contando com mais de 100 mil empregados, entre próprios e terceiros.

"A Vale acredita que o crescimento orgânico é a principal alavanca de geração de valor", afirma o profissional entrevistado da área de planejamento, GPE, corroborado pelo volume e pelo montante que a empresa tem investido em projetos nos últimos anos. Para crescer e ser excelente, a Vale tem se empenhado tanto em melhorar a utilização dos ativos existentes quanto em expandir esta base. Desta forma, a empresa possui um significativo portfólio de projetos a ser desenvolvido nos próximos anos por meio de seus ativos de classe mundial, embora não descarte a possibilidade de realizar aquisições adicionais.

Como uma empresa listada no Brasil e em Nova York, suas práticas de governança corporativa atendem a todas as regulamentações da CVM (Comissão de Valores Mobiliários do Brasil) e da SEC (Comissão de Valores Mobiliários dos EUA), pelas quais se orientam.

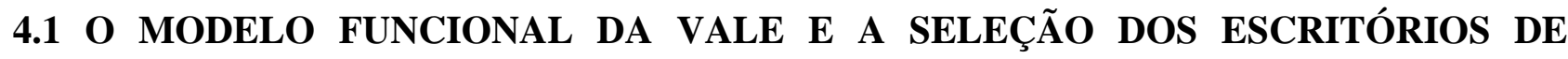 PROJETOS}

Combinando sua meta de crescimento e excelência com um cenário de atuação altamente aquecido em função das economias emergentes, a Vale possui um expressivo portfólio de projetos. A geração e a gestão deste portfólio, no entanto, não obedecem a um padrão corporativo. Dentro de um ciclo institucional de planejamento estratégico, cada área ou departamento desdobra para si as metas estratégicas da empresa, em função das respectivas atividades-fim. As metas departamentais,

Revista de Gestão e Projetos - GeP, São Paulo, v. 2, n. 2, p 26-54, jul./dez. 2011. 
por sua vez, dão origem a um conjunto de projetos que devem contribuir para o atingimento dos objetivos estratégicos da Companhia.

O tamanho das carteiras de projetos e do investimento associado (11 bilhões de dólares em 2008 e 14, 2 bilhões já aprovados para 2009, dedicados à execução de projetos), sua natureza diversificada, a demanda crescente por capacitação, a necessidade de informações e controles consolidados, sugerem a complexidade que a atividade alcançou na Vale (GPE).

Para maximizar a gestão de projetos nos diversos departamentos foram criados vários Escritórios de Projetos na Vale, com diferentes motivações, atribuições, abrangência e reporte hierárquico-funcional. Foram identificados nove Escritórios de Projetos formais e atuantes na empresa, assim distribuídos nos três grupos funcionais da Vale: quatro na operação, três na administração e dois em serviços compartilhados.

\subsection{O ESCRITÓRIO DE GESTÃO DE PROJETOS DA OPERAÇÃO}

A gerência de departamento que abriga o escritório de projetos tem como missão “implantar projetos com as melhores práticas de engenharia, priorizando saúde, segurança e meio ambiente; atendendo às expectativas dos clientes; alinhado com o planejamento estratégico da Vale" (VALE, 2008). Tem como visão "obter, até 2010, a excelência em implantação de projetos, atingindo as metas estabelecidas pela Vale" (VALE, 2008).

O escritório de gestão de projetos pesquisado na operação, como todos os escritórios de projetos identificados na Vale, é conhecido como "PMO XXXX" - a sigla de Project Management Office associada às quatro letras que identificam o departamento ao qual respondem na empresa. Para efeito deste estudo, dado que este PMO foi selecionado como representante do conjunto de PMO’s que atuam na operação, será chamado simplesmente de PMO OPE, daqui em diante.

O PMO OPE já nasceu com seu foco tático-metodológico definido em função de ter sido criado por meio de um projeto e com o desafio de "contribuir para uma reversão radical da imagem da engenharia de projetos, que havia perdido sua estrutura e seu know-how ao longo da gestão anterior", discorre GE1.

O grande objetivo do Projeto PMO, portanto, é "elevar grau de maturidade da gerência de departamento em gestão de projetos até o nível (metodologicamente) padronizado”, aponta EE3 com corroboração de GE2. O projeto foi iniciado em setembro de 2006 e o escopo inicial da célula PMO OPE prevê sua implementação em três ondas com diferentes metas, em um projeto com três

Revista de Gestão e Projetos - GeP, São Paulo, v. 2, n. 2, p 26-54, jul./dez. 2011. 
anos de duração, 2007-2009. A primeira onda, chamada de "ganhos rápidos", focou seus esforços nas melhorias metodológicas passíveis de implantação com ganhos imediatos, enquanto se detalhava e validava com os patrocinadores, o plano do projeto. A segunda onda, batizada de "processos críticos", está focada na construção e definição dos principais processos da gestão de projetos, incorporando as nove áreas de conhecimento preconizadas pelo PMI e duas complementares, saúde e segurança e meio ambiente, dentro do modelo de gestão por processos adotados pelo departamento. A terceira onda ou "novos processos e melhorias", planeja revisitar as definições anteriores e incorporar o aprendizado do período, devendo ser iniciada em novembro de 2008. No período de duração do projeto estão previstas avaliações de efetividade, utilização, satisfação da metodologia e PMO, além do nível de maturidade da área.

O PMO OPE possui uma equipe de 5 profissionais e sua estrutura funcional é mista, ou seja, composta por uma combinação de 2 empregados Vale e 4 profissionais contratados de empresas terceiras, geralmente, consultorias.

Nível de Atuação: O portfólio de projetos do PMO OPE 2008 é composto por projetos de investimento corrente, em sua maioria, e de capital (com orçamento menor do que cem milhões de reais), que correspondem a $60 \%$ dos investimentos do departamento, aproximadamente 200 milhões de reais. São cerca de 80 projetos de engenharia, de execução complexa e variados níveis de criticidade para as metas do negócio, que chegaram à etapa de construção.

Os projetos de investimentos correntes se distribuem em três programas: (1) substituição de equipamentos pesados em final de vida útil, (2) ambiental, de grande visibilidade e impacto social e de (3) automação, focados na revitalização elétrica da infra-estrutura existente, em função de obsolescência e novos regulamentos.

Com grande rotatividade, a área apresentava problemas como baixa motivação dos profissionais, perda de conhecimento técnico e lições aprendidas em projetos anteriores, ausência de um modelo de gestão de projetos definido, falta de uma estrutura dedicada: "tudo isso gerou a necessidade de criarmos rotinas, de definirmos procedimentos, capacitarmos as pessoas e o PMO nos pareceu a estratégia correta para isso", completa este gestor, devidamente afinado com as informações prestadas por EE3 e GE2.

Atribuições: Com um escopo definido no documento que formalizou o início do Projeto PMO, o escritório OPE possui responsabilidades bem definidas e fortemente orientadas para gerar, 
capacitar, disciplinar e acompanhar o departamento em termos de sua metodologia de gestão de projetos. Não possui nenhuma responsabilidade executiva sobre qualquer fase do ciclo de vida dos projetos de sua carteira, nem responsabilidade sobre os resultados que estes alcancem, informa GE1.

A missão deste PMO, formalmente documentada e divulgada, é "implementar metodologias para assegurar maturidade em gestão de projetos desta gerência de departamento", enquanto sua visão está orientada para "garantir a utilização das melhores práticas em Gestão de Projetos, na área, até 2010" (VALE, 2008). Suas funções, portanto, são quase exclusivamente orientadas para atender ao foco metodológico (definição de padrões de gestão de projetos, disseminação de melhores práticas, desenvolvimento de competências e capacitação), em nível da carteira da gerência de departamento ou divisão. Caracterizadamente, trata-se de um PMO de tipologia clássica quanto às suas atribuições.

A atuação inicialmente centrada em questões metodológicas, além de ser a principal ambição a ser atendida na implantação, ainda inibia as resistências naturais dos gerentes responsáveis pelo gerenciamento dos respectivos projetos. "Naquele momento, a expectativa por uma gestão de pipeline, por uma visão consolidada do portfólio do departamento mal aparecia”, comenta GE2, "mas neste momento, é para onde estamos olhando".

A quase exclusividade do foco metodológico deste PMO pode sugerir alguma fragilidade para um escritório de Nível dois, porém os novos desafios inseridos em seu escopo de atuação a pedido do diretor do departamento deverão conduzir a um novo conjunto de atribuições, aumentando a adequação e consistência das atribuições em relação ao posicionamento encontrado. Os recursos do PMO são oriundos de seu orçamento aprovado do próprio projeto.

Alinhamento com o Negócio: “O PMO foi criado por uma necessidade do negócio: melhorar a performance do departamento quanto ao desempenho físico financeiro e econômico dos projetos", revela GE1.

Uma vez que a abrangência de atuação do PMO OPE envolve as gerências de departamento que respondem, sob a forma de projetos, por $60 \%$ dos investimentos do departamento, buscar a excelência em gestão de projetos como meta estratégica parece, mais do que uma ambição, uma necessidade. O volume financeiro, a carteira de projetos, a missão da gerência de departamento que abriga o PMO e o objetivo estratégico do departamento, combinados, explicam e reforçam o perfil da estrutura criada, bem como sua orientação para atingimento dos resultados esperados.

Revista de Gestão e Projetos - GeP, São Paulo, v. 2, n. 2, p 26-54, jul./dez. 2011. 
Se por um lado o PMO OPE compartilha, com as demais gerências do departamento, as metas de aderência e efetividade no uso da metodologia desenvolvida, por outro lado, não tem nenhum vínculo direto com os resultados alcançados na atuação executiva destas gerências em seus projetos. Como a visão de projetos não é sistêmica ou integrada em relação ao seu ciclo de vida (princípio-meio-fim), nem em nível do departamento, nem da organização, ao receber os projetos na etapa de "contratar e construir", a atuação do PMO OPE se limita, muitas vezes, à execução das entregas previstas. A interface com as fases anteriores de desenvolvimento do projeto é pontual, informal e, habitualmente, reativa, comprometendo, muitas vezes, a qualidade da entrega assim como a satisfação do cliente com a mesma, ou ainda o compromisso destas áreas clientes com a realização do projeto como planejado (tempo, custo, prioridade).

O PMO OPE não tem nenhum tipo de participação na definição ou priorização da carteira que cuidadosamente, monitora, metodologicamente. Sua modelagem e implementação revelam um grande alinhamento em relação aos objetivos estratégicos do departamento, mas, não necessariamente, em relação à carteira que é objeto de sua atuação. Carteira esta, composta por um conjunto de projetos sobre os quais o PMO OPE não exerce nenhum tipo atuação quanto à sua aderência aos objetivos da organização ou do departamento: monitora, criteriosamente, sua conformidade em relação aos padrões metodológicos, mas não sua orientação ou seus resultados.

Resultados do PMO OPE: Verificações mensais geram um indicador de aderência à metodologia que reflete o percentual de cumprimento das definições metodológicas implementadas por projeto, consolidando e reportando o resultado, por programa, aos principais envolvidos. Este indicador de aderência associado a um índice de participação das demais gerências de departamento no desenvolvimento dos processos do projeto e, ainda, ao cumprimento dos prazos, compõe o indicador PMO. Este indicador faz parte da remuneração variável de todos os empregados do departamento.

"Do jeito que a gente fez aqui é sustentável, envolve as pessoas que se apropriam da metodologia, participam. Depois destes dois anos, todos são donos do PMO”, comenta EE3. Sua estratégia de implementação privilegiou a busca pela excelência em projetos, suprindo as demandas por padrões e processos, especialmente aqueles demandados e/ou críticos para os clientes do escritório de projetos.

Tal estratégia, além de não se comprometer com o tratamento do legado, não conflita com os resultados efetivos nem se responsabiliza pela consolidação e reporte do status dos projetos, sendo, 
portanto, confortável para as áreas executivas. Mas são estes mesmos profissionais, os gestores de projetos, os componentes majoritários dos quase 30 grupos que estão desenvolvendo os processos críticos e melhorias na metodologia do projeto, o que conduz a um alto nível de participação e compromisso com a implementação subsequente.

Ao final do projeto, o material gerado será consolidado em um manual contendo toda a metodologia, documentando e divulgando toda a padronização de processos implementados. Este resultado, conforme reforça GE2, foi facilitado por "um trabalho muito forte de comunicação, de gestão da mudança, além do patrocínio do diretor do complexo”.

O PMO OPE está posicionado, em relação ao tipo de carteira atendido, às expectativas organizacionais a serem atendidas e ao posicionamento na hierarquia, como um PMO Nível dois, de acordo com o proposto por Bridges e Crawford (2001). Ainda assim, seu principal traço se manifesta no foco "puro" de suas atribuições, claramente metodológico, revelando um "tipo clássico" de PMO, como entende Dinsmore (2003).

O nível de atuação e as atribuições do PMO OPE estão alinhados com negócio, e dado que o Projeto PMO é um dos objetivos estratégicos do departamento, desdobrados do plano estratégico da Vale, a configuração encontrada é adequada para contribuir com o atingimento dos objetivos estratégicos da organização.

\subsection{O ESCRITÓRIO DE GESTÃO DE PROJETOS DA ADMINISTRAÇÃo}

O departamento selecionado como representante da administração na Vale é responsável por maximizar a transformação da tecnologia da automação em performance operacional. A área, sediada no Rio de Janeiro, responde hierarquicamente ao diretor-presidente da Vale e sua equipe é composta por 22 empregados e, aproximadamente, 200 contratados de terceiros para prestação de serviços relativos à gestão, monitoramento e controle de projetos. A missão deste departamento é "aplicar tecnologias de automação, contribuindo para a excelência da performance operacional, segurança ocupacional e sustentabilidade ambiental" (VALE, 2008). E sua visão é "atingir a excelência na transformação da tecnologia da automação em performance operacional" (VALE, 2008).

São três os pilares estratégicos do departamento: (1) garantir que a tecnologia de automação esteja funcionando corretamente e dando suporte para as operações adequadamente; (2) aplicar a tecnologia de automação para levar a performance das operações da companhia e (3) promover a

Revista de Gestão e Projetos - GeP, São Paulo, v. 2, n. 2, p 26-54, jul./dez. 2011. 
introdução de tecnologias de automação inovadoras que possam criar um diferencial competitivo na performance operacional da Vale. A partir desses pilares, o departamento definiu e organizou o escopo de sua atuação por meio de um conjunto de projetos a serem realizados, em etapas, de 2008 a 2014. Seu portfólio é composto por oito grandes programas distribuídos entre os seguintes temas: confiabilidade dos ativos; gestão operacional; eficiência energética; suporte à manutenção e saúde e segurança.

Os investimentos em tecnologia de automação seguem, portanto, uma estratégia de priorização de programas tecnológicos que se traduz no portfólio de projetos planejados. "Nosso negócio", afirma o GA3, "é business improvement, buscar qualquer melhoria do negócio calcada em tecnologia de automação, através de projetos". Tal estratégia, busca promover o atingimento do nível inovador pelas áreas operacionais Vale, superando tanto o nível tradicional, atual, quanto o avançado, por meio da transformação de processos e tecnologia inovadora.

O escritório de projetos deste departamento, conhecido como PMO ou PMO ADM, como será tratado daqui em diante, foi criado junto com o departamento, em julho de 2006. Nasceu focado no acompanhamento e gestão de projetos de automação de processos, o que já era uma “cultura do próprio diretor em funções e projetos anteriores", comenta GA2.

Nível de atuação: A carteira de projetos ou Portfólio 2008 do PMO ADM é composta por cerca de 130 projetos classificados pelo departamento como estratégicos e um orçamento de investimentos de cerca de 300 milhões de reais. Os recursos financeiros do Escritório de Projetos são próprios, oriundos do investimento aprovado para o portfólio, alocados em orçamentos específicos por projeto e programa, conforme informa GA1.

A principal motivação para criação do PMO ADM foi a necessidade de confiabilidade e regularidade na geração de informações sobre o andamento da carteira de projetos da área demandada pelo diretor, visando a tomada de decisão em nível executivo. Um passo adiante levou a identificação de demandas organizacionais em vários níveis também por transparência e maior previsibilidade na implantação dos projetos aprovados, e consequentemente, dos investimentos envolvidos, motivando sua implementação e influenciando em sua configuração. Seu posicionamento na estrutura hierárquico-funcional da Vale corresponde ao nível de departamento ou divisão.

Revista de Gestão e Projetos - GeP, São Paulo, v. 2, n. 2, p 26-54, jul./dez. 2011. 
A localização do PMO ADM na estrutura hierárquico-funcional da organização é pertinente para atender às necessidades de visão consolidada da carteira, integração de requisições, reporte, orçamento e dar consistência ao processo entre múltiplos projetos e interfaces do departamento.

Atribuições: As atribuições do PMO ADM apontam para um perfil de atuação diferenciado entre os níveis local, tático e estratégico. As funções do PMO Local estão circunscritas aos projetos do local em que está fisicamente instalado e estão concentradas no foco operacional, com algum viés de suporte metodológico para os Gerentes de Projeto. O PMO Tático e o PMO Estratégico já atuam com foco predominantemente estratégico, ainda que o primeiro privilegie a visão e o suporte dos programas enquanto o segundo o faz focado na carteira de projetos.

A atuação do PMO Tático abrange tanto o status de um programa em toda geografia na qual está sendo implantado, quanto de todos os oito programas em uma única localidade, enquanto o PMO Estratégico atua "avaliando as iniciativas em andamento sob o ponto de vista do conjunto, do contexto esperado pelo portfólio", comenta o GA1, para facilitar a tomada de decisão sobre as tendências encontradas.

Um primeiro olhar sobre as atribuições encontradas no PMO ADM sugere uma ênfase em alguns papéis, especialmente monitoramento, controle e reporte nos três níveis de atuação (projetos, programas e portfólio) em detrimento, por exemplo, de funções com foco metodológico que poderiam garantir um diferencial competitivo para um departamento, cuja missão está assentada na gestão de projetos. Iniciativas de capacitação e educação continuada ou o estabelecimento de políticas e padrões para execução e gestão de projetos, por exemplo, não estão inseridas no escopo de atuação do PMO ADM. Tampouco foram identificadas funções relacionadas ao foco tático, como gestão integrada de recursos ou sistemáticas de seleção, categorização e priorização de projetos.

$\mathrm{Na}$ verdade, uma análise desvinculada do nome "PMO" sugere que toda a gerência de departamento dedica-se, exclusivamente, ao conjunto de atividades relacionadas a um Escritório de Projetos. Registra-se a existência de uma área focada na gestão do conhecimento e melhores práticas em gestão de projetos (responsável por todas as definições metodológicas), outra focada na definição e manutenção do portfólio de projetos e sua gestão econômica, e ainda uma terceira divisão focada na gestão da mudança, tanto dos impactos organizacionais quanto individuais. Tal análise permite uma compreensão adequada da configuração do PMO ADM, a partir de limites mais flexíveis que incluam uma avaliação das atribuições da área como um todo. Assim, mais do

Revista de Gestão e Projetos - GeP, São Paulo, v. 2, n. 2, p 26-54, jul./dez. 2011. 
que um PMO com configuração adequada, evidencia-se uma gerência de departamento com configuração adequada para contribuir para a geração de resultados desejada pelo departamento.

Alinhamento com o negócio: Uma vez que os pilares estratégicos do departamento foram estabelecidos a partir das estratégias formais de crescimento da Vale, e que estes são a base para a definição da carteira de projetos sob responsabilidade do escritório de projetos da administração, o alinhamento do PMO ADM com o negócio pôde ser facilmente estabelecido.

Para definição dos investimentos em tecnologia de automação é promovida uma seleção e priorização de iniciativas propostas pelas áreas operacionais em parceria com este departamento, evidenciando-se a participação da estrutura na tomada de decisão sobre os projetos.

A carteira de projetos ou o portfólio do departamento é composta por projetos distribuídos em oito programas tecnológicos, que refletem temas priorizados pela operação para viabilizar o crescimento orgânico da Vale. Esta composição reflete uma forte aderência aos grandes objetivos organizacionais e departamentais.

"A atuação do PMO deve promover parcerias e compromisso", afirma GA2, "mas os resultados serão alcançados pela área operacional”. Muitas vezes os projetos, assim como os objetivos das áreas, se misturam e sua contribuição para os resultados alcançados pelas áreas operacionais torna-se difícil de ser mensurada.

Resultados do PMO ADM: Embora trabalhe com algumas métricas tradicionais para avaliar status e evolução dos projetos e programas, o indicador mais claro da atuação do PMO é o aumento da previsibilidade na sua execução da carteira. "O PMO ADM trouxe tranquilidade", como afirma GA1, "comparabilidade", como acredita GA3, estabelecendo um processo de gestão acompanhamento, monitoramento, controle e reporte, essencialmente, sistematizado, transparente e confiável. O uso da informação pelos vários níveis de gestão no departamento e áreas parceiras confirma esta ideia, associada a um desempenho reconhecidamente melhor na gestão e execução de projetos pelo terceiro ano consecutivo, completa o diretor.

Sua estratégia de implementação foi reativa, focada em atender, primeiramente, às demandas do diretor do departamento e patrocinador do PMO, por isenção e confiabilidade das informações, e gradativamente buscando suprir as demandas por padrões, informações e recursos dos demais clientes do escritório de projetos.

Revista de Gestão e Projetos - GeP, São Paulo, v. 2, n. 2, p 26-54, jul./dez. 2011. 
O PMO ADM está posicionado, em relação ao tipo de carteira atendido, expectativas organizacionais a serem atendidas e posicionamento na hierarquia, tipicamente como um PMO Nível dois (BRIDGES e CRAWFORD, 2001). Sua criação está caracterizadamente associada ao desdobramento da estratégia da organização no departamento, seja esta consequência do mercado aquecido ou simplesmente acelerada por este contexto.

Se suas atribuições revelam uma ênfase concentrada nos focos operacional e estratégico, as lacunas em relação a funções de natureza metodológica e tática são supridas pelas demais áreas existentes na mesma gerência de departamento que o abriga, inibindo qualquer fragilidade que este desenho encontrado possa sugerir. O conjunto de funções, híbrido, mostra-se em consonância com as proposições de Dinsmore (2003) e Hill (2008).

O alinhamento do escritório de projetos com o negócio do departamento é deliberado, como pode ser averiguado por seus pilares estratégicos e seu desenho funcional. A configuração da gerência de departamento, mais do que exclusivamente do PMO ADM, é que, manifestadamente, está orientada para favorecer o atingimento das metas organizacionais e departamentais.

\subsection{O ESCRITÓRIO DE GESTÃO DE PROJETOS DE SERVIÇOS COMPARTILHADOS}

O Centro de Serviços Compartilhados ou CSC, como é mais conhecido, mais do que uma unidade de negócio é um modelo de operação que gerencia processos de suporte comuns a todas ou a muitas das unidades de negócio da Vale, com o objetivo de sustentar o crescimento e o processo de internacionalização da Vale, implantado em julho de 2007. Focado no aumento da performance resultante da especialização e do ganho em escala, este departamento sediado no Rio de Janeiro, responde hierarquicamente a um diretor de departamento global. A missão do departamento é "prestar serviços às unidades de negócio com alta qualidade e custos competitivos, atendendo plenamente as expectativas dos clientes" (VALE, 2008). E ampara sua visão "ser reconhecida pela excelência na prestação de serviços para todas as empresas do Grupo CVRD no Brasil e no exterior", declara EC3.

O CSC padronizou os processos de suporte para toda companhia e criou uma estrutura formal de serviço com canais bem definidos de atendimento. Com esta estrutura, o CSC busca maior controle no cumprimento das normas da Vale e maior autonomia para escolha de serviços por parte das Unidades de Negócio, facilitando ainda o processo de internacionalização da empresa para os outros países.

Revista de Gestão e Projetos - GeP, São Paulo, v. 2, n. 2, p 26-54, jul./dez. 2011. 
A implementação do modelo de global sharing services é um dos pilares da estratégia da Vale, exatamente em função do processo de internacionalização previsto em sua estratégia de crescimento no longo prazo. Derivado deste conceito, este departamento elaborou um Plano Estratégico Quinquenal para ser executado até 2012, contemplando as grandes iniciativas para garantir a implementação, replicação e sustentação do modelo.

O modelo conceitual do CSC estabelece um alinhamento estratégico, anual, como ponto de partida para a definição do planejamento estratégico do departamento. Neste alinhamento, o mapa estratégico Vale é desdobrado em um mapa estratégico de serviços compartilhados, no qual são definidas as grandes linhas de ação a serem seguidas pelo departamento no ano seguinte.

“O mapa estratégico da CSC é a base para definição de seu portfólio, em que são selecionadas e priorizadas as iniciativas e projetos que realmente estão vinculados à estratégia CSC, que estão focados nos objetivos definidos para o ano", argumenta GC2, em concordância com GC1. O PMO CSC é parte integrante da dinâmica de operacionalização dos objetivos da Vale, ocupandose do monitoramento e controle da carteira do departamento, composto por programas e projetos voltados para inovação ou melhorias dos processos e tecnologia

O principal papel do PMO CSC é "garantir a execução da carteira de projetos, dentro do escopo, tempo e custos definidos”, suportando a implantação e o crescimento do CSC, afirma GC2. Dar visibilidade interna aos resultados alcançados, promover a sinergia entre os projetos e eliminar distâncias entre as interfaces envolvidas, são outras expectativas para a atuação do escritório explicitadas no modelo de gestão.

Nível de atuação: A carteira de projetos atendida pelo PMO CSC é composta pelo conjunto de projetos estratégicos para o departamento, com eventual condução de projetos críticos ou em situação crítica. São aproximadamente 200 projetos e cerca de 170 milhões de reais. A falta de informação sobre a situação dos projetos, e por extensão, sobre a carteira; atrasos nas entregas; mudanças constantes no escopo e, consequentemente, aumento de custos; falta de padrões para gerenciamento dos projetos, enfim, “dificuldades características de uma baixa maturidade em gestão de projetos", ponderou GC2, foram os principais motivadores para a criação do PMO CSC.

“A necessidade de garantir a execução dos projetos e a realização dos investimentos, historicamente baixa na Vale, para o Programa CSC", assim como promover uma seleção estruturada e aderente aos objetivos definidos pelo departamento, assinala GC1, foram demandas da organização e do departamento a serem atendidas pela estrutura. Seu posicionamento na hierarquia

Revista de Gestão e Projetos - GeP, São Paulo, v. 2, n. 2, p 26-54, jul./dez. 2011. 
funcional da Vale corresponde ao nível de departamento ou divisão. Se, hierarquicamente, o PMO responde a uma gerência de departamento, funcionalmente, reporta-se ao diretor global de serviços compartilhados e diretores de departamento.

Atribuições: As atribuiçõos do Escritório de Projetos CSC estão fortemente associadas ao foco operacional (suporte, planejamento e controle de projetos) e metodológico (definição de padrões de gestão de projetos, disseminação de melhores práticas e capacitação). "Sua independência em relação às estruturas executoras de iniciativas e projetos garante isenção e autonomia em suas análises e reporte", como indica EC3.

O monitoramento, controle e reporte mensal do progresso físico-financeiro dos projetos, assim como dos investimentos em custeio da carteira são funções que se evidenciam dentre aquelas mapeadas pelos três entrevistados. No foco metodológico, destaca-se a implementação e manutenção de padrões e procedimentos de gestão de projetos para todos os projetos da CSC.

Do foco tático, identifica-se a função de gestão de projetos, que embora pontual e eventual, no momento da pesquisa estava sendo realizada para sete projetos classificados como "críticos para o negócio" e para dois programas, compostos por 11 projetos, por estarem em situação crítica ou problemática. A ênfase na aderência da carteira aos objetivos estratégicos da área assim como a coordenação do processo de seleção e priorização, explicitam o foco estratégico de sua atuação, cujo conjunto de atribuições, centrado em nível da carteira do departamento, revela-se visivelmente compatível com o posicionamento do PMO CSC no Nível dois.

Alinhamento com o negócio: Partindo da premissa de que a própria implementação do departamento, ou de seu modelo de operação, é um pilar estratégico para a internacionalização e crescimento da Companhia, por definição, todos os programas e projetos que viabilizam tal implementação favorecem ao atingimento das metas em nível da organização e do departamento.

O planejamento estratégico anual da área, não obstante, é realizado a partir do desdobramento do mapa estratégico da organização e conta com a participação do departamento de planejamento estratégico Vale para geração do mapa estratégico do departamento, apontaram os profissionais GC1 e GPE. Este mapa é o insumo primário para a definição dos projetos e iniciativas que compõem o portfólio CSC, confirmando o alinhamento da carteira com o negócio bem como o potencial do escritório de projetos na realização dos objetivos estratégicos definidos.

A motivação para criação do PMO, centrada na garantia de realização das iniciativas, tanto quanto na aderência destas iniciativas aos objetivos estratégicos da organização e do departamento, 
também evidenciam o forte alinhamento com o negócio. Os empregados entrevistados explicitam em sua fala o quanto este alinhamento é orientado para os objetivos organizacionais e o quanto esta forte associação é percebida: "planejamento e projetos andam juntos, por dever de ofício a gente sabe com certeza para onde a empresa quer ir", diz EC3. "Nós não sabemos apenas o que (quais projetos) será feito, mas porque deve ser feito, onde queremos chegar”, completa GE1.

Resultados do PMO CSC: Os resultados atingidos pelo PMO CSC são acompanhados mensalmente por meio de indicadores chave previstos no modelo de gestão para esta estrutura, essencialmente focados na execução financeira e física dos projetos. Também são realizadas pesquisas junto aos clientes internos em relação à prestação de serviços do escritório.

Ainda assim, em termos metodológicos, por exemplo, "há muito que se evoluir para o estabelecimento de uma cultura de projetos efetiva", reconhece GC2, em concordância com GC1 e EC3. E há uma expectativa de co-responsabilidade com as áreas executoras dos projetos para intensificar o compromisso e otimizar os resultados desejados, uma evolução esperada de seu papel, manifestada pelo responsável pelo escritório de gestão de projetos CSC.

Há uma clara associação da estratégia organizacional com a criação do próprio departamento, assim como da estrutura responsável pelo controle da realização do Programa que o criou: o PMO CSC. O PMO CSC está posicionado, tipicamente, como um PMO Nível dois. Suas atribuições exemplificam com grande nitidez sua atuação nos quatro focos, mas, indicam, simultaneamente, oportunidades de reflexão nas quais suas funções ainda guardam características de um escritório cuja atuação está em nível do desenvolvimento do projeto, ou seja, no nível um. (BRIDGES e CRAWFORD, 2001; DINSMORE, 2003). O alinhamento do PMO CSC com o negócio Vale é intrínseco à natureza de sua atuação e sua configuração direcionada para contribuir, favoravelmente, para que a organização e o departamento alcancem seus objetivos.

O quadro 03 apresenta uma avaliação comparativa entre os três escritórios de projetos descritos anteriormente.

Revista de Gestão e Projetos - GeP, São Paulo, v. 2, n. 2, p 26-54, jul./dez. 2011. 


\begin{tabular}{|c|c|c|c|c|}
\hline $\begin{array}{c}\text { DIMENSÃO DA } \\
\text { CONFIGURAÇÃO }\end{array}$ & $\begin{array}{c}\text { VARIÁ VEIS } \\
\text { OPERACIONAIS }\end{array}$ & PMO OPE & PMO ADM & PMO CSC \\
\hline \multirow{4}{*}{$\begin{array}{l}\text { NÍVEL DE } \\
\text { ATUAÇÃO }\end{array}$} & $\begin{array}{l}\text { Tipo de carteira } \\
\text { atendida }\end{array}$ & $\begin{array}{l}\text { - Portfólio de } \\
\text { projetos do depto } \\
\text { ou divisão }\end{array}$ & $\begin{array}{l}\text { - Portfólio de } \\
\text { projetos do } \\
\text { departamento }\end{array}$ & $\begin{array}{l}\text { - Portfólio de } \\
\text { projetos do } \\
\text { depto / } \\
\text { Programa CSC }\end{array}$ \\
\hline & $\begin{array}{l}\text { Motivação para } \\
\text { implementação }\end{array}$ & $\begin{array}{c}\text { - Atender a um } \\
\text { objetivo estratégico } \\
\text { do depto } \\
\text { - Insucessos e } \\
\text { resultados ruins GP }\end{array}$ & $\begin{array}{l}\text { • Falta de } \\
\text { confiabilidade, } \\
\text { regularidade e } \\
\text { isenção das } \\
\text { informações }\end{array}$ & $\begin{array}{l}\text { - Dificuldades } \\
\text { na GP } \\
\bullet \text { Não } \\
\text { realização do } \\
\text { investimento } \\
\text { aprovado } \\
\end{array}$ \\
\hline & $\begin{array}{l}\text { Posicionamento } \\
\text { hierárquico- } \\
\text { funcional na } \\
\text { estrutura Vale }\end{array}$ & $\begin{array}{c}\bullet \text { Em nível de } \\
\text { departamento ou } \\
\text { divisão }\end{array}$ & $\begin{array}{c}\text { • Em nível de } \\
\text { departamento ou } \\
\text { divisão }\end{array}$ & $\begin{array}{l}\text { - Em nível de } \\
\text { departamento } \\
\text { ou divisão }\end{array}$ \\
\hline & $\begin{array}{l}\text { Equipe e estrutura } \\
\text { funcional }\end{array}$ & $\begin{array}{c}\text { - Mista ( } 2 \text { Vale e } 4 \\
\text { contratados) } ; \\
\text { única }\end{array}$ & $\begin{array}{l}\text { - Mista ( } 1 \text { Vale e } \\
21 \text { contratados); } \\
\text { em } 3 \text { níveis, } \\
\text { vários locais }\end{array}$ & $\begin{array}{l}\bullet \text { Vale, } 5 \\
\text { empregados; } \\
\text { única }\end{array}$ \\
\hline \multirow{3}{*}{ ATRIBUIÇÕES } & $\begin{array}{l}\text { Porte quantitativo e } \\
\text { financeiro da } \\
\text { carteira }\end{array}$ & $\begin{array}{c}\text { - } \mathrm{R} \$ 200 \mathrm{MM} \text { e } 80 \\
\text { projetos/ } 3 \\
\text { programas }\end{array}$ & $\begin{array}{c}\bullet \mathrm{R} \$ 300 \mathrm{MM} \text { e } \\
130 \text { projetos / } 8 \\
\text { programas }\end{array}$ & $\begin{array}{c}-\mathrm{R} \$ 170 \mathrm{MM} \text { e } \\
200 \text { projetos/ } 1 \\
\text { programas }\end{array}$ \\
\hline & $\begin{array}{c}\text { Autonomia na } \\
\text { gestão de recursos }\end{array}$ & $\begin{array}{l}\text { - Sim, recursos do } \\
\text { Projeto PMO }\end{array}$ & $\begin{array}{l}\text { - Sim, recursos } \\
\text { dos projetos }\end{array}$ & $\begin{array}{l}\text { - Sim, recursos } \\
\text { próprios }\end{array}$ \\
\hline & Foco de atuação & $\begin{array}{c}\text { - Metodológico, } \\
\text { pontualmente tático }\end{array}$ & $\begin{array}{c}\text { - Operacional } \\
\text { Nível } 1 \\
\text { - Operacional, } \\
\text { metodológico e } \\
\text { estratégico Nível } \\
2 \\
\end{array}$ & $\begin{array}{l}\text { - Operacional } \\
\text { Nível } 1 \\
\text { - Nos } 4 \text { focos } \\
\text { em Nível } 2\end{array}$ \\
\hline \multirow{3}{*}{$\begin{array}{l}\text { ALINHAMENTO } \\
\text { COM O NEGÓCIO }\end{array}$} & $\begin{array}{l}\text { Estratégia de } \\
\text { Implementação }\end{array}$ & $\begin{array}{c}\text { - Patrocínio } \\
\text { executivo } \\
\text { - Foco não conflita } \\
\text { com áreas } \\
\text { executoras projetos }\end{array}$ & $\begin{array}{c}\text { - Patrocínio } \\
\text { executivo } \\
\text { - Reativa, } \\
\text { orientada pela } \\
\text { demanda do DI } \\
\end{array}$ & $\begin{array}{l}\text { - Patrocínio } \\
\text { executivo } \\
\text { Controle } \\
\text { financeiro da } \\
\text { carteira } \\
\end{array}$ \\
\hline & $\begin{array}{l}\text { Compromisso com } \\
\text { os resultados da } \\
\text { carteira }\end{array}$ & $\begin{array}{l}\bullet \text { Não } \\
\text { • Indicador de } \\
\text { aderência comum } \\
\text { com à divisão }\end{array}$ & $\begin{array}{l}\text { - Parcial, por } \\
\text { meio das metas } \\
\text { do depto }\end{array}$ & $\begin{array}{l}\text { - Total, por } \\
\text { meio das metas } \\
\text { do depto }\end{array}$ \\
\hline & $\begin{array}{c}\text { Participação nas } \\
\text { decisões sobre a } \\
\text { carteira }\end{array}$ & • Não & $\begin{array}{c}\text { - Sim, "voz, vez } \\
\text { e voto" }\end{array}$ & $\begin{array}{l}\text { - Sim, por meio } \\
\text { de forte } \\
\text { integração com } \\
\text { Planej. } \\
\text { Estratégico }\end{array}$ \\
\hline
\end{tabular}

Revista de Gestão e Projetos - GeP, São Paulo, v. 2, n. 2, p 26-54, jul./dez. 2011. 


\begin{tabular}{|l|l|c|c|c|}
\hline & $\begin{array}{c}\text { Resultados } \\
\text { alcançados }\end{array}$ & $\begin{array}{c}\bullet \text { Índice de } \\
\text { maturidade subiu } \\
\text { de 2,22 para 2,82 }\end{array}$ & $\begin{array}{c}\text { Monitoramento, } \\
\text { controle e reporte } \\
\text { padronizados } \\
\bullet \text { Maior } \\
\text { previsibilidade }\end{array}$ & $\begin{array}{c}\bullet \text { 95\% execução } \\
\text { financeira }(68 \% \\
\text { média histórica } \\
\text { Vale) }\end{array}$ \\
\hline
\end{tabular}

Quadro 3 - Resumo das Dimensões de Configuração dos Escritórios de Projetos Fonte: Elaborado pelos autores.

\section{CONSIDERAÇÕES FINAIS}

Para atender ao crescente volume de projetos, com alta complexidade técnica, prazos de implementação apertados e expressivos investimentos de recursos - demandas derivadas do contexto então vivido pela indústria mineral, tornou-se imperativo para as áreas da Vale melhorarem a qualidade e os resultados da gestão de seus projetos.

Para favorecer a realização dos devidos planos estratégicos, as áreas estudadas na operação, administração e serviços compartilhados da Vale, dentre outras iniciativas, optaram pela implementação de unidades estruturais focadas no suporte e gestão de projetos: os Escritórios de Projetos. Ao examinar a configuração destes Escritórios de Projetos, foi possível constatar que a estratégia Vale, desdobrada por cada departamento estudado em função de sua missão específica, foi o fator determinante desta implementação e norteou o desenho destas estruturas para atender às respectivas necessidades em gestão de projetos. Caracterizando-se a criação dos escritórios de projetos na estrutura dos três departamentos e a influência da estratégia, do departamento e da organização, na configuração destes escritórios.

A configuração dos Escritórios de Projeto analisados é peculiar, modelada individual e independentemente das demais estruturas de projetos da organização. Embora fortemente alinhada com os objetivos estratégicos do departamento ao qual pertence, a atuação dos três escritórios diverge claramente em relação à suas atribuições, foco e estratégia de implementação, mas é convergente em relação à obtenção de resultados para seu respectivo departamento.

Tal desenho, encontrando alternativas customizadas para manter a orientação e a atuação aderente aos objetivos definidos por cada departamento, mostra-se, genericamente, adequado quanto ao nível de atuação, atribuições e alinhamento. Porém, uma configuração adequada não é, necessariamente, uma configuração ótima, que maximize os recursos e o desempenho em projetos do departamento ou da organização.

Revista de Gestão e Projetos - GeP, São Paulo, v. 2, n. 2, p 26-54, jul./dez. 2011. 
Nas três áreas estudadas, há uma clara percepção de valor agregado ao departamento pela atuação do Escritório de Projetos, que se traduz por algum tipo de melhoria em seus resultados: na operação, pelo amadurecimento da competência do departamento em gestão de projetos; na administração, pela maior previsibilidade dos projetos geridos bem como pela aderência da carteira aos objetivos da área; e em serviços compartilhados, pela melhor performance físico-financeira da carteira.

Não obstante, mensurar a contribuição efetiva destes Escritórios quanto aos resultados conquistados pelo departamento ou pela organização, é um grande desafio. As diferenças na configuração dos Escritórios, tanto quanto a falta de padrões institucionais na gestão de projetos, ou ainda, a inexistência de uma gestão integrada da carteira de projetos da Vale, são aspectos que dificultam a obtenção desta medida.

\section{REFERÊNCIAS}

Barcaui, A. B. Perfil dos Escritórios de Projetos em organizações atuantes no Brasil. 151. Dissertação (Mestrado). Universidade Federal Fluminense. Niterói, 2003.

Bridges, Dianne N.; Crawford, J. Kent. A Project Office - where and what type. Proceedings of the Project Management Institute Annual Seminars \& Symposium. Nashville, Tenn.. Nov 1-10, 2001.

Bridges, Dianne N.; Crawford, J. Kent. How to Startup and Rollout a Project Office. Proceedings of the Project Management Institute Annual Seminars \& Symposium. Houston, Sep 7-16, 2000.

Casey, William; Peck, Wendi. Choosing the rigth PMO setup. PM Network Magazine, february, 2001.

Crawford, J. Kent. The Strategic Project Office: a guide to improving organizational performance. New York: Marcel Dekker, Inc., 2002.

Departamento Nacional de Produção Mineral. Informe mineral. 2007- $1^{\circ}$ semestre. Brasília, DF: DNPM, 2007a.

Dinsmore, P. C. Transformando estratégias empresariais em resultados através da gerência por projetos. Rio de Janeiro: Qualitymark Ed., 2003.

Revista de Gestão e Projetos - GeP, São Paulo, v. 2, n. 2, p 26-54, jul./dez. 2011. 
Englund, R. L.; Graham, R.J.; Dinsmore, P. Creating the Project Office: a manager's guide to leading organizational change. San Francisco: Jossey-Bass Bussiness \& Management Series, 2003.

Hill, Gerard M. The complete project management office handbook. $2^{\mathrm{a}}$ ed. New York: Auerbach Publications, 2008.

Kerzner, H. Gestão de Projetos: as melhores práticas. Trad. Marco Antonio Viana Borges, Marcelo Klippel e Gustavo Severo de Borba. Porto Alegre: Bookman, 2002.

Kerzner, H. Project management: a systems approach to planning, scheduling and controlling. $8^{\text {a }}$ ed. New Jersey: Jonh Wiley \& Sons, Inc., 2003.

King, W. R. The role of projects in the implementation of business strategy. In.: Cleland, D.I.; King, W.R. Project management handbook. New York, NY: Van Nostrand Reinhold, 1993.

Prado, Darci. Gerenciamento de projetos nas organizações. Belo Horizonte: Desenvolvimento Gerencial, 2000.

Project Management Institute - PMI. Um Guia do Conjunto de Conhecimentos do Gerenciamento de Projetos (PMBoK Guide). 3ª . Edição. Newton Square, Pennsylvania: PMI, 2004.

Project Management Institute - PMI. The Standard for Program Management. Newton Square, Pennsylvania: PMI, 2006a.

Rabechini Jr, R. O Gerente de Projetos na Empresa. São Paulo: Atlas, 2003.

Rad, Parviz F., Levin, Ginger. The Advanced Project Management Office: a comprehensive look at function and implementation. Florida: CRC Press LCC, 2002.

Sbragia, R.; Gonzales, F.; Rodrigues, I. Escritório de Gerenciamento de Projetos. In: XXII Simpósio de Gestão da Inovação Tecnológica, 2002, Salvador, Bahia, 6 a 8 de novembro, 2002.

Vale. Companhia Vale do Rio Doce. Apresenta estrutura, governança, informações, produtos e serviços oferecidos pela empresa. Disponível em: <www.vale.com>. Acesso em 19/04/2008.

Valeriano, D. Moderno gerenciamento de projetos. São Paulo: Prentice Hall, 2005.

Vargas, Ricardo Viana. Gerenciamento de Projetos: Estabelecendo Diferenciais Competitivos. 6 ed. Atual. Rio de Janeiro: Brasport, 2003.

Revista de Gestão e Projetos - GeP, São Paulo, v. 2, n. 2, p 26-54, jul./dez. 2011. 
Verzuh, Eric. MBA Compacto em Gestão de Projetos. $6{ }^{a}$ ed. Rio de Janeiro: Campus, 2000.

Data do recebimento do artigo: 26/09/2011

Data do aceite de publicação: 16/11/2011

Revista de Gestão e Projetos - GeP, São Paulo, v. 2, n. 2, p 26-54, jul./dez. 2011. 